\title{
Manipulation of Schwann cell migration across the astrocyte boundary by polysialyltransferase- loaded superparamagnetic nanoparticles under magnetic field
}

\author{
This article was published in the following Dove Press journal: \\ International Journal of Nanomedicine \\ 12 December 2016 \\ Number of times this article has been viewed
}

\author{
Bing Xia* \\ Liangliang Huang* \\ Lei Zhu \\ Zhongyang Liu \\ Teng Ma \\ Shu Zhu \\ Jinghui Huang \\ Zhuojing Luo \\ Department of Orthopaedics, Xijing \\ Hospital, Fourth Military Medical \\ University, Xi'an, Shaanxi, People's \\ Republic of China \\ *These authors contributed equally \\ to this work
}

Correspondence: Jinghui Huang;

Zhuojing Luo

Department of Orthopaedics, Xijing

Hospital, Fourth Military Medical

University, 169 Changle West Road,

Xi'an, Shaanxi 7I0032, People's

Republic of China

Tel/fax +86 2984775285

Email huangjh@fmmu.edu.cn;

zjluo@fmmu.edu.cn

\begin{abstract}
Schwann cell (SC) transplantation is an attractive strategy for spinal cord injury (SCI). However, the efficacy of SC transplantation has been limited by the poor migratory ability of SCs in the astrocyte-rich central nervous system (CNS) environment and the inability to intermingle with the host astrocyte. In this study, we first magnetofected SCs by polysialyltransferasefunctionalized superparamagnetic iron oxide nanoparticles (PST/SPIONs) to induce overexpression of polysialylation of neural cell adhesion molecule (PSA-NCAM) to enhance SC migration ability, before manipulating the direction of SC migration with the assistance of an applied magnetic field (MF). It was found that magnetofection with PST/SPIONs significantly upregulated the expression of PSA-NCAM in SCs, which significantly enhanced the migration ability of SCs, but without preferential direction in the absence of MF. The number and averaged maximum distance of SCs with PST/SPIONs migrating into the astrocyte domain were significantly enhanced by an applied MF. In a $300 \mu \mathrm{m}$ row along the astrocyte boundary, the number of SCs with PST/SPIONs migrating into the astrocyte domain under an MF was 2.95 and 6.71 times higher than that in the absence of MF and the intact control SCs, respectively. More interestingly, a confrontation assay demonstrated that SCs with PST/SPIONs were in close contact with astrocytes and no longer formed boundaries in the presence of MF. In conclusion, SCs with PST/SPIONs showed enhanced preferential migration along the axis of a magnetic force, which might be beneficial for the formation of Büngner bands in the CNS. These findings raise the possibilities of enhancing the migration of transplanted SCs in astrocyte-rich CNS regions in a specific direction and creating an SC bridge in the CNS environment to guide regenerated axons to their distal destination in the treatment of SCI.
\end{abstract}

Keywords: Schwann cell, astrocyte, magnetic field, superparamagnetic iron oxide nanoparticles, spinal cord injury, cell orientation

\section{Introduction}

Cell transplantation therapy is an attractive strategy for nerve repairs and functional recovery after spinal cord injury (SCI). ${ }^{1}$ Thus far, various cell types have been used for SCI treatment, including oligodendrocytes, Schwann cells (SCs), olfactory ensheathing cells, and stem cells., ${ }^{2,3}$ SCs are among the most promising candidates for transplantation, as they can form Büngner bands serving as substrates for axonal elongation, provide multiple neurotrophic factors, and remyelinate the regenerated and demyelinated axons, necessary for nerve regeneration and functional recovery. ${ }^{4,5}$ However, one major issue yet to be addressed is the poor integration of transplanted 
SCs into the astrocyte-rich central nervous system (CNS), primarily due to their limited motility in the CNS environment. SCs do not intermingle with astrocytes; ${ }^{6}$ they are walled-off by astrocytes, and their migration in the CNS is thereby limited by astrocytes. ${ }^{7}$ The prevention of SC migration from the transplantation site restricts them from guiding regenerated axons to enter the caudal spinal cord and impairs their ability to mediate remyelination..$^{8-10}$

To solve this problem, SCs genetically modified to alter their adhesive properties have been investigated. ${ }^{11-13}$ In vertebrates, the neural cell adhesion molecule (NCAM) is expressed on axonal and $\mathrm{SC}$ membranes, and its function is influenced by polysialylation, a critical mediator of neural cell migration. ${ }^{12}$ Polysialic acid (PSA) is a linear homopolymer of $\alpha 2,8-\mathrm{N}$ acetylneuraminic acid, which is synthesized on NCAM by polysialyltransferase (PST) and sialyltransferase X (STX). ${ }^{14,15}$ Expression of PSA on NCAM is upregulated during the development of the CNS and downregulated postnatally, except in a few brain regions that retain the ability of physiological plasticity. ${ }^{16}$ Studies have demonstrated that the expression of PSA on SCs driven by PSTs lasts for much longer periods, ${ }^{17}$ and PST-modified SCs induce overexpression of polysialylation of NCAM (PSA-NCAM), which is a useful strategy to enhance their integration and migration in the injured CNS. ${ }^{16}$ The enhanced migration achieved by PST-modified SCs shows no preferred direction; the efficacy of this strategy for guiding regenerated axons to their destination, the caudal spinal cord, is compromised in large measures.

With the development of nanotechnology and molecular biology, superparamagnetic iron oxide nanoparticles (SPIONs) have become increasingly well recognized as not only promising non-virus gene transfection vectors ${ }^{17-20}$ but also an attractive approach to drive cell migration in a desired direction under an applied magnetic field (MF). ${ }^{21}$ SPIONs have already been approved by the US Food and Drug Administration (FDA) as safe magnetic resonance imaging (MRI) contrast agents and have many advantages over other gene carriers, such as protecting genes from digestion, low immunogenicity, and potential for clinical application. Formation of SPIONs with exogenous target gene protects the gene against nuclease degradation after introduction into cells. The superparamagnetic component enables the SPIONs/gene complex to respond to an external MF, which speeds up the targeting and sedimentation of the gene on the cell surface and reduces the duration of the transfection procedure, resulting in increased cellular endocytosis of the PST and higher efficiency of exogenous gene expression. ${ }^{22-24}$ The surface of the SPIONs was further furnished with a cationic polymer, polyethylenimine (PEI), to produce a positive surface suitable for cellular internalization. Furthermore, the internalized PEI-coated SPIONs (PEI-SPIONs) can exert cellular tension under an applied MF, which sufficiently initiates axonal outgrowth and cell migration in the desired direction. ${ }^{25-27}$

In this study, we first attempted to improve the migration of SCs by transferring PST into them, using PEI-SPIONs as gene vectors. After magnetofection, a static MF was applied to activate the magnetic vectors to generate cellular tension, in turn orientating the migration of cells along a specific direction. This study sought to establish a new strategy to improve the integration of SCs into the astrocyte-rich CNS, thus promoting the efficacy of SCs in the treatment of SCI.

\section{Materials and methods Synthesis of the PEI-SPIONs/PST complexes and PEI-SPIONs/DNA complexes}

The PEI-SPIONs ( $1 \mu \mathrm{g} / \mu \mathrm{L})$ (Chemicell, Berlin, Germany) comprised $\mathrm{Fe}_{3} \mathrm{O}_{4}$ nanoparticles with branched PEI (25 kDa) as surface modification. The complementary DNA (cDNA) encoding rat PST, ST8Sia IV (1,365 bp; accession number: NM_053914), was inserted into a pcDNA3.1 transfer plasmid (Genomeditech, Shanghai, China) between its unique EcoRI and BamHI cutting sites (PST plasmid). For comparison, a control pcDNA3.1 transfer plasmid (Genomeditech) encoding no target gene was also synthesized (DNA plasmid). PEI-SPIONs and PST or DNA plasmids were diluted with different volumes of distilled water to form different weight ratios of complexes at $\mathrm{pH} 7.4$ and then mixed and incubated at room temperature for $30 \mathrm{~min}$ to form complexes.

\section{Characterization of PEI-SPIONs}

The morphology, distribution, and average size of PEISPIONs were analyzed by transmission electron microscopy (TEM; H-600; Hitachi, Tokyo, Japan). The zeta potential and size distribution of the PEI-SPIONs were evaluated at $20^{\circ} \mathrm{C}-25^{\circ} \mathrm{C}$ using a zeta potential/nanometer particle size analyzer (DelsaNano; Beckman Coulter, Brea, CA, USA).

\section{Isolation and purification of primary SCs and astrocytes}

Primary rat SCs were prepared from the sciatic nerves and brachial plexuses of postnatal day 1-3 Sprague Dawley rats, following the protocol described previously. ${ }^{28}$ All experimental procedures were performed in accordance with the Guide for the Care and Use of Laboratory Animals 
(National Institutes of Health Publication No 85-23, revised 1985) and approved by the Animal Research Committee of The Fourth Military Medical University, People's Republic of China. In brief, sciatic nerves and brachial plexuses of postnatal day 1-3 Sprague Dawley rats (provided by the Experimental Animal Center of the Fourth Military Medical University) were finely minced with scalpel blades on culture dishes and then digested with $0.25 \%$ trypsin and $0.03 \%$ collagenase (Sigma-Aldrich, St Louis, MO, USA) at $37^{\circ} \mathrm{C}$ for $26 \mathrm{~min}$. Cells were then incubated in Dulbecco's Modified Eagle's Medium (DMEM; Thermo Fisher Scientific Inc., Waltham, MA, USA) containing $15 \%$ fetal calf serum (FCS; Thermo Fisher Scientific Inc.) and 1\% antibiotics (penicillin and streptomycin solution). Twenty-four hours after seeding, the cells were treated with the antimitotic agent cytosine arabinoside $\left(10^{-5} \mathrm{M}\right)$ for $48 \mathrm{~h}$ to inhibit fibroblast proliferation. After this, cells were sustained in DMEM supplemented with $15 \% \mathrm{FCS}, 2 \mathrm{mM} / \mathrm{mL}$ forskolin (Sigma-Aldrich), and $20 \mu \mathrm{g} / \mathrm{mL}$ bovine pituitary extract (Biomedical Technologies Inc., Stoughton, MA, USA). The final preparations consisted of a high purity $(>96 \%)$ of SCs (Figure 1A-D).
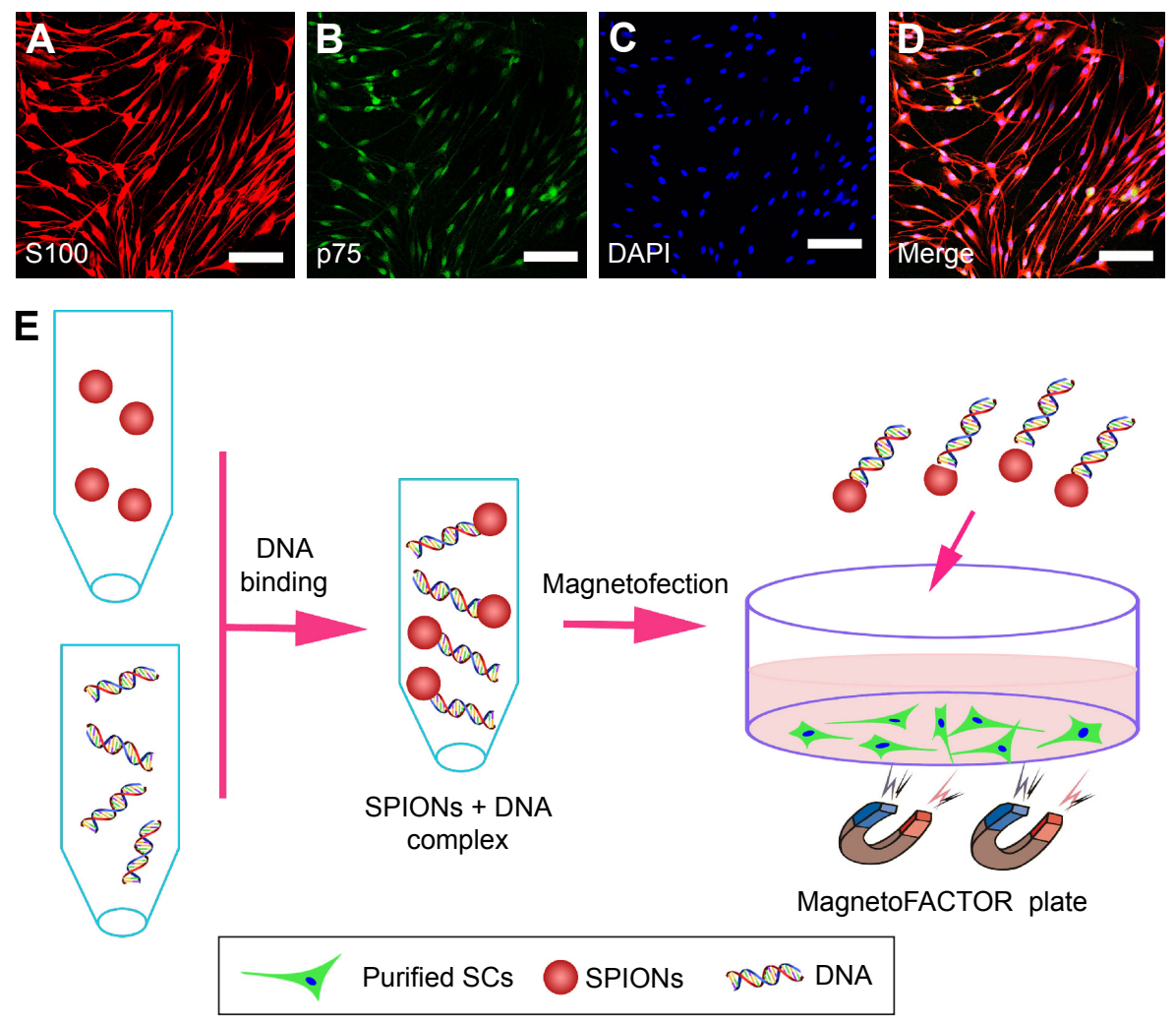

Figure I Characterization of SCs and schematic representation of magnetofection.

Notes: Double immunofluorescent staining showed the expression of SI00 (A) and p75 (B) with DAPI nuclear counterstaining (C). Merge file showed a purity of $>96 \%$ SCs (D). Schematic of cell magnetofection (E). Scale bars: (A-D) $100 \mu \mathrm{m}$.

Abbreviations: DAPI, 4',6-diamidino-2-phenylindole; SCs, Schwann cells; SPIONs, superparamagnetic iron oxide nanoparticles. 
plasmid solution was added to $8 \mu \mathrm{L}$ of PEI-SPIONs solution $(1 \mu \mathrm{g} / \mu \mathrm{L})$ and mixed immediately by vigorous pipetting. The mixture was then incubated for $30 \mathrm{~min}$ at room temperature to allow PEI-SPIONs/cDNA complexes to form by virtue of the efficient binding of cDNA to the magnetic nanoparticles.

Primary SCs were seeded in a six-well plate, cultured in DMEM containing 15\% FBS, and grown until they reached $70 \%-80 \%$ confluence. Prior to transfection, cells were rinsed twice with phosphate-buffered saline (PBS) or DMEM without serum or other supplement, before the medium was replaced with $1.8 \mathrm{~mL}$ fresh serum-free medium per well. The prepared PEI-SPIONs/PST complex or PEI-SPIONs/DNA complex solutions were added to the six-well cell culture plate at a volume of $200 \mu \mathrm{L}$ per well. After mixing, the six-well cell culture plate was placed on top of a commercial magnetic neodymium-iron-boron ( $\mathrm{NdFeB}$ ) multiwell plate (MagnetoFACTOR-96 plate; Chemicell), the strength of which was $0.3 \mathrm{~T}$, for $4 \mathrm{~h}$ of incubation at $37^{\circ} \mathrm{C}$ in an atmosphere containing $5 \% \mathrm{CO}_{2}$. The polarity of the MagnetoFACTOR-96 plate is alternated north and south. Its special geometry ensures strong and equal application of the MF under each well.

After transfection, the medium was replaced with fresh serum-containing medium, and the magnetofected SCs with PEI-SPIONs/PST complexes (PEI-SPIONs/PST/SC) or magnetofected SCs with PEI-SPIONs/DNA complexes (PEI-SPIONs/DNA/SC) were cultured for further use.

\section{CCK-8 assays}

Cell viability and cytotoxicity were analyzed using the Cell Counting Kit 8 (CCK-8; Dojindo, Kumamoto, Japan) according to the manufacturer's instructions. Briefly, different concentrations of PEI-SPIONs $(0,1,2,4$, and $8 \mu \mathrm{g} / \mathrm{mL})$ were magnetofected into SCs in a 96-well plate. After incubation for 24 or $72 \mathrm{~h}$, SCs were washed three times with PBS; then, $100 \mu \mathrm{L}$ of fresh medium with $10 \mu \mathrm{L}$ of CCK- 8 reagent was added to each well and incubated at $37^{\circ} \mathrm{C}$ under humidified $5 \% \mathrm{CO}_{2}$ for $4 \mathrm{~h}$. Absorbance was measured at $450 \mathrm{~nm}$ using a microplate reader.

\section{Live-dead assay}

To further evaluate the cytotoxicity of PEI-SPIONs, livedead assays were performed using a live-dead cell imaging kit (Thermo Fisher Scientific Inc.) according to the manufacturer's instructions. Live cells were stained by Live-Dye ${ }^{\mathrm{TM}}$, a green fluorescent dye (excitation/emission: 488/518 nm), and dead cells were stained by propidium iodide, a red fluorescent dye (excitation/emission: 488/615 nm). Briefly, different concentrations of PEI-SPIONs (0, 1, 2, 4, and $8 \mu \mathrm{g} / \mathrm{mL}$ ) were magnetofected into SCs. After incubation for 24 or $72 \mathrm{~h}$, the cells were washed three times with sterilized PBS before the staining solution was added. Cellular viability was then analyzed by counting the live and dead cells after incubation for $15 \mathrm{~min}$ at $37^{\circ} \mathrm{C}$. The number of living (green) or dead (red) cells were counted using Image Pro Plus software (Media Cybernetics, Bethesda, MI, USA).

\section{Electron microscopic analysis of PEI- SPIONs magnetofected SCs}

To observe the morphology of magnetofected SCs, we seeded primary cells on coverslips pre-coated with PLL and then treated with PEI-SPIONs $(4 \mu \mathrm{g} / \mathrm{mL})$. At $6 \mathrm{~h}$ after magnetofection, the cells were rinsed with PBS, fixed, and dehydrated with serial ethanol solutions. Cells were then dried under vacuum atmosphere at room temperature and sputter-coated with gold; after these procedures, the specimens were viewed under a scanning electron microscope (SEM; S-3400N; Hitachi).

For observing the localization of PEI-SPIONs in SCs, primary SCs were seeded on a six-well plate and then treated with PEI-SPIONs $(4 \mu \mathrm{g} / \mathrm{mL})$. After $24 \mathrm{~h}$ incubation, cells were prepared according to a standard protocol ${ }^{29}$ for TEM imaging (H-600; Hitachi) before examination with the said microscope.

\section{Gene expression analysis}

Seventy-two hours after the magnetofection of different concentrations of PEI-SPIONs $(0,1,2,4$, and $8 \mu \mathrm{g} / \mathrm{mL})$ to SCs, the SCs were first counted and then homogenized in Trizol reagent (Sigma-Aldrich). Total RNA was isolated and normalized to cell numbers. cDNA was synthesized using Superscript III reagents (Thermo Fisher Scientific, Waltham, MA, USA) according to the manufacturer's instructions. Quantitative real-time polymerase chain reaction (qRT-PCR) analysis was then performed. The sequence of primers for PST $5^{\prime}$ to $3^{\prime}$ was upper: GAAAAGAAACCCGAGCCCCA; lower: AGGCTC CGTTTTGGGGAAAT. The qRT-PCR parameters used were denaturation at $95^{\circ} \mathrm{C}, 30 \mathrm{~s}$; primer annealing at $59^{\circ} \mathrm{C}, 30 \mathrm{~s}$; and elongation products at $72^{\circ} \mathrm{C}, 40 \mathrm{~s}$. Acquired PCR products were quantified using the $2-\Delta \Delta \mathrm{Ct}$ method. The housekeeping gene ACTB was used to normalize quantities of messenger RNA (mRNA). Assays were performed three times.

\section{Western blotting assays}

At $72 \mathrm{~h}$ after magnetofection, cultures were washed twice with PBS and lysed in lysis buffer (20 mM Tris- $\mathrm{HCl}$ [pH 7.5], 
$150 \mathrm{mM} \mathrm{NaCl}, 1 \mathrm{mM} \mathrm{Na} \mathrm{N}_{2}$-ethylene diamine tetraacetic acid, $1 \mathrm{mM}$ ethylene glycol tetraacetic acid, $2.5 \mathrm{mM}$ sodium pyrophosphate, $1 \mathrm{mM}$ beta-glycerophosphate, $1 \%$ Triton $\mathrm{X}-100,1 \mathrm{mM} \mathrm{Na}_{3} \mathrm{VO}_{4}, 1 \mathrm{mM}$ phenylmethylsulfonyl fluoride, and $1 \mathrm{mg} / \mathrm{mL}$ leupeptin) for $10 \mathrm{~min}$ at $4^{\circ} \mathrm{C}$. SC lysates were collected and subjected to centrifugation at $4^{\circ} \mathrm{C}$ for $10 \mathrm{~min}$. Total protein concentration was then determined by the bicinchoninic acid (BCA) assay. The samples were separated by sodium dodecyl sulfate polyacrylamide gel electrophoresis (SDS-PAGE) and transferred onto the nitrocellulose membrane. The membrane was blocked with $5 \%$ non-fat dry milk in TBST buffer ( $50 \mathrm{mM}$ Tris- $\mathrm{HCl}, 100 \mathrm{mM}$ $\mathrm{NaCl}$, and $0.1 \%$ Tween-20, $\mathrm{pH} 7.4$ ) at $4^{\circ} \mathrm{C}$ overnight. After blocking, appropriate amounts of primary mouse monoclonal anti-PSA-NCAM antibody $(1: 1,000$; Chemicon, Pittsburgh, PA, USA) and the internal reference rabbit anti-GAPDH polyclonal antibody (1:500; Santa Cruz Biotechnology Inc, Santa Cruz, CA, USA) were added before incubation at room temperature for $2 \mathrm{~h}$. The membrane was washed three times with $0.1 \%$ PBS, 5 min per wash. Horseradish peroxidaseconjugated secondary antibodies were added prior to incubation at room temperature for $1 \mathrm{~h}$. The membrane was then washed three times with $0.1 \%$ PBS, 5 min per wash. The membranes were examined for immunoreactive proteins with enhanced chemiluminescence (ECL), using Tanon 4100 and analyzed by Tanon Gls-1000 system. GAPDH was used as an internal control.

\section{Inverted coverslip migration assays}

The inverted coverslip assays were carried out as described previously. ${ }^{5}$ The SCs were trypsinized with $0.1 \%$ trypsin and then resuspended at a density of $2 \times 10^{6}$ cells $/ \mathrm{mL}$. SCs, PEISPIONs/DNA/SCs, or PEI-SPIONs/PST/SCs were plated onto coverslip fragments $\left(\sim 5 \mathrm{~mm}^{2}\right)$ pre-coated with PLL. The fragments were sustained in the culture medium for $24-36 \mathrm{~h}$ until SCs were confluent, after which the coverslips were washed with HBSS three times to remove any unattached cells and then inverted with cells facing downward onto the astrocyte monolayer. An external static magnet (neodymium cube magnet; grade N48; cube side length: $50 \mathrm{~mm}$; magnetic strength: $1.4 \mathrm{~T}$ ) was placed parallel to one edge of the coverslip fragment that was marked for further analysis. Seventy-two hours were allowed for cell migration; then, cells were fixed and the distance of cell migration away from the edge of the fragment was analyzed. The maximum distance of the migrated SCs from the marked edge was measured, and the number of migrated SCs at specific migrating distance was counted within $500 \mu \mathrm{m}$ rows. Meanwhile, the angle $\theta$ between the long axis of each migrated $\mathrm{SC}$ and the direction of MF outward were also measured. SC migration orientation was quantified as an orientation index defined as $\mathrm{Oi}=\cos (\theta)$, with the angle $0<\theta<\pi / 2$ (Oi=1 when the direction of SC migration overlaps with the MF direction). For each experiment, over six areas were randomly selected, and an average of 50 $\mathrm{SCs}$ were measured for each area. All the migration assays were performed under the condition of mitotic inhibition by aphidicolin $(1.5 \mu \mathrm{g} / \mathrm{mL})$ to be certain that movement away from the coverslip was not due to proliferation.

\section{SC and astrocyte confrontation assays}

Confrontation assays were carried out as described previously. ${ }^{12,30}$ Briefly, $10 \mu \mathrm{L}$ strips containing $1 \times 10^{4}$ astrocytes or $3 \times 10^{4} \mathrm{SCs}$ were plated parallel to each other on PLL-coated coverslips. Cells were allowed to attach for $1 \mathrm{~h}$ before washing with $0.1 \%$ PBS to remove unattached cells. The applied MF was placed parallel to the SC strip in the astrocyte side. Cells were maintained in DMEM/15\% FCS for $7 \mathrm{~d}$ to migrate toward each other. Cells were then fixed and immunolabelled using anti-glial fibrillary acidic protein (anti-GFAP; astrocytes) and anti-S100 (SCs) as described later. The total number of SCs that crossed the cell boundary and migrated into the astrocyte domains was counted and averaged over six randomly chosen areas per condition.

\section{Immunofluorescent staining}

Cells were fixed by $4 \%$ paraformaldehyde for $15 \mathrm{~min}$ at room temperature, washed, and blocked in $0.2 \%$ Triton X-100 and $10 \%$ normal goat serum for $1 \mathrm{~h}$. Cells were then incubated with primary polyclonal rabbit anti-S100 protein antibody (1:100; Abcam, Cambridge, UK), polyclonal mouse antip75 antibody (1:50; Abcam), polyclonal chicken anti-GFAP antibody (1:1,000; Abcam), or monoclonal mouse anti-PSANCAM antibody (1:200; Merck Millipore, Billerica, MA, USA) overnight at $4^{\circ} \mathrm{C}$. Cells were then incubated with indocarbocyanine-conjugated goat anti-chicken $(1: 1,000$; Abcam), indocarbocyanine-conjugated goat anti-mouse (1:1,000; Abcam), or fluorescein-conjugated goat anti-rabbit $\left(1: 1,000\right.$; Abcam) secondary antibodies for $2 \mathrm{~h}$ at $37^{\circ} \mathrm{C}$. Thereafter, the cell nucleus was stained with 4',6-diamidino2-phenylindole (DAPI) solution (1:500; Sigma-Aldrich) for $5 \mathrm{~min}$ at room temperature. The primary anti-p 75 and anti-S100 antibodies were used for identifying SCs, antiGFAP antibodies were used for identifying astrocytes, and anti-PSA-NCAM antibodies were used to detect the expression of PSA-NCAM. The results of immunostaining were 
examined by a fluorescence microscope (FV-1000; Olympus,

Tokyo, Japan).

\section{Statistical analysis}

Acquired data were expressed as mean \pm standard deviation (SD) and analyzed using one-way analysis of variance (ANOVA) with the SPSS 13.0 software package (IBM Corporation, SPSS Statistics, Chicago, IL, USA). The values of $\mathrm{Oi}$ were expressed as their respective medians and interquartile ranges. Statistically significant results were subjected to Tukey's post hoc test (GraphPad Prism 5.0; GraphPad Software, Inc, La Jolla, CA, USA). Dunnett's test was also used. Values of $P<0.05$ were considered statistically significant.

\section{A}

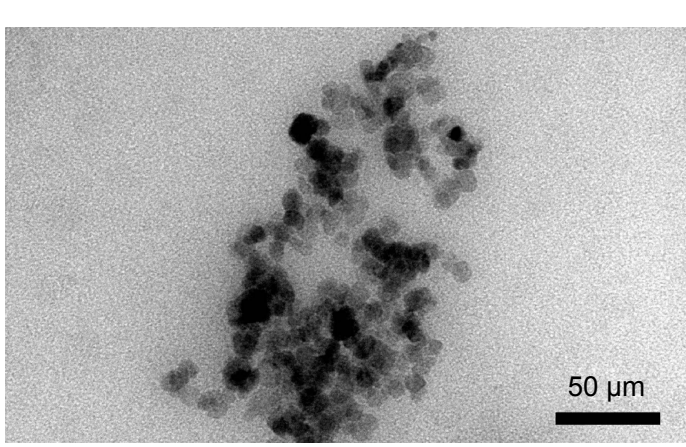

C

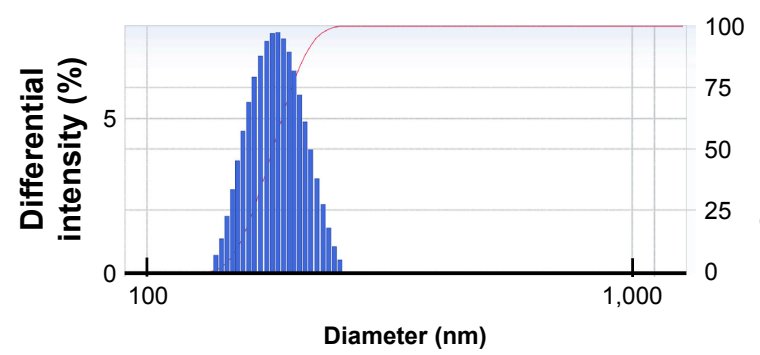

E

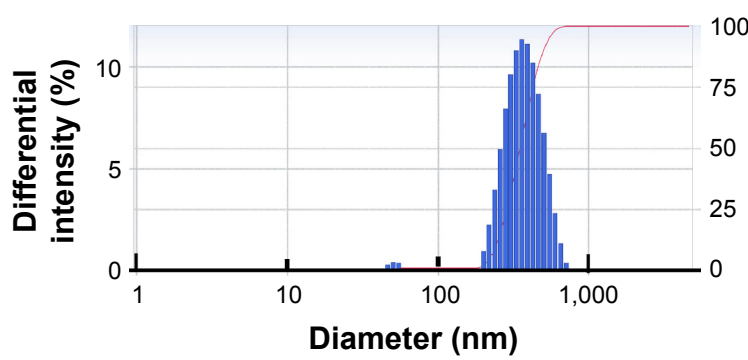

\section{Results}

\section{Characterizations of PEI-SPIONs and} PEI-SPIONs/PST complexes

The particle size and morphology of PEI-SPIONs were analyzed by TEM. The average diameter of PEI-SPIONs was $\sim 28.1 \pm 3.6 \mathrm{~nm}$ (Figure 2A). The saturation magnetization at $3.382 \mathrm{Oe}$ was $61.62 \mathrm{emu} / \mathrm{g}$ (Figure 2B). In order to evaluate the plasmid-binding ability of PEI-SPIONs, the surface charge and hydrodynamic diameter measurements of PEI-SPIONs and PEI-SPIONs/PST complexes were examined by a ZetaPALS particle size analyzer. PEI-SPIONs had an average diameter of 186.5 $\pm 23.4 \mathrm{~nm}$ (Figure 2C) and a positive charge of $19.20 \pm 3.2 \mathrm{mV}$ (Figure 2D). PEI-SPIONs/ PST complexes were found to have an average diameter

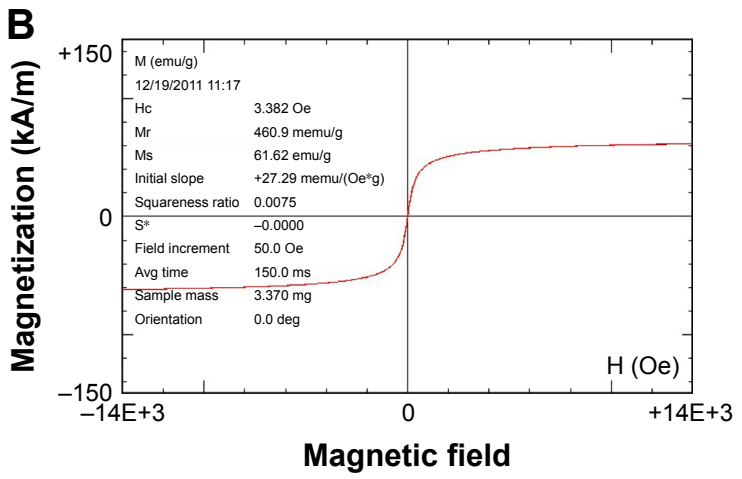

D

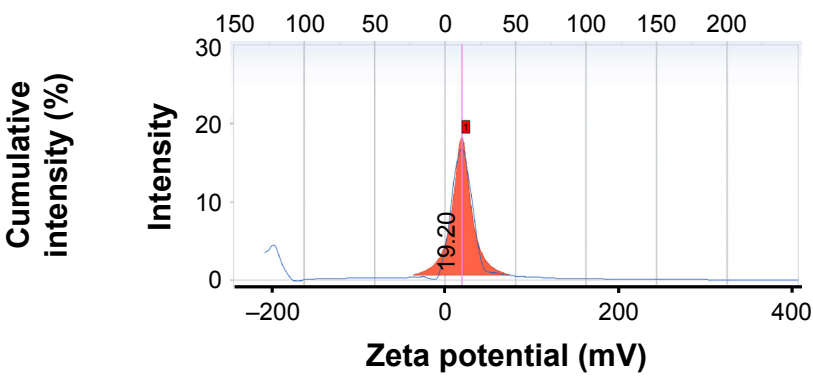

$\mathbf{F}$

Frequency $\mathbf{( H z )}$

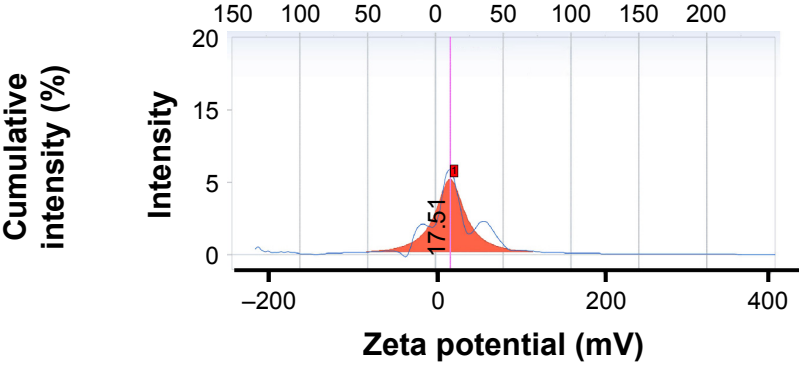

Figure 2 Characterization of PEI-SPIONs.

Notes: (A) TEM analysis of PEI-SPIONs. (B) The magnetization parameters of PEI-SPIONs. (C) The overall distribution of PEI-SPIONs sizes. (D) The zeta potential of PEI-SPIONs. (E) The overall distribution of PEI-SPIONs/PST complex sizes. (F) The zeta potential of PEI-SPIONs/PST complex.

Abbreviations: Avg, average; PEI-SPIONs, polyethylenimine-coated superparamagnetic iron oxide nanoparticles; TEM, transmission electron microscopy. 
of $378.8 \pm 109.1 \mathrm{~nm}$ (Figure 2E) and a positive charge of $17.51 \pm 2.4 \mathrm{mV}$ (Figure 2F). The discrepancy between the average diameter of PEI-SPIONs as determined by TEM and ZetaPALS can be explained by the agglomeration of charged PEI-SPIONs in the preparation of sample solution for ZetaPALS analysis. ${ }^{31-33}$ These results demonstrated that PEI-SPIONs/PST complex is still positively charged and suitable for cellular internalization.

\section{Magnetofection of SCs}

Previous study demonstrated that PEI-SPIONs were detected on the surface of magnetofected cell membrane $2 \mathrm{~h}$ after magnetofection and gradually began to move into the cytoplasm $6 \mathrm{~h}$ after magnetofection. Additionally, most PEI-SPIONs were inside the nucleus $12-18 \mathrm{~h}$ after magnetofection. ${ }^{34}$ Thus, we performed SEM examination to detect PEI-SPIONs on the cell membrane $6 \mathrm{~h}$ after magnetofection and TEM examination to detect PEI-SPIONs in the cytoplasm $24 \mathrm{~h}$ after magnetofection. At $6 \mathrm{~h}$ after the magnetofection of SCs (PEI-SPIONs, $4 \mu \mathrm{g} / \mathrm{mL}$ ), particles were observed by SEM to be on the surface of SCs, while those particles were not seen on normal control SCs (Figure 3A-C). At $24 \mathrm{~h}$ after magnetofection, a cluster of particles was observed to localize within the cytoplasm of SCs, indicating that PEISPIONs had already attached to the cell surface and localized intracellularly by endocytosis (Figure 3D-F).

\section{Cytotoxicity analysis of PEI-SPIONs}

At 24 and $72 \mathrm{~h}$ after magnetofection, the cytotoxicity of PEI-SPIONs was evaluated by CCK-8 assay. No significant difference of cell viability was found between PEI-SPIONs concentrations of $0,1,2$, and $4 \mu \mathrm{g} / \mathrm{mL}$ at 24 and $72 \mathrm{~h}$ after magnetofection. However, cell viability was significantly decreased by $19 \%$ and $22 \%$ when PEI-SPIONs concentration was increased to $8 \mu \mathrm{g} / \mathrm{mL}$ at 24 and $72 \mathrm{~h}$ after magnetofection (Figure 4L). At $24 \mathrm{~h}$ after magnetofection, the percentage of dead cells was $\sim 3 \%-5 \%$ at concentrations of PEI-SPIONs ranging from 0 to $4 \mu \mathrm{g} / \mathrm{mL}$. The percentage of dead cells at $72 \mathrm{~h}$ after magnetofection was not significantly different from that at $24 \mathrm{~h}$ (Figure $4 \mathrm{~K}$ ). The percentage of dead cells increased to $6.4 \% \pm 1.03 \%$ and $6.6 \% \pm 1.16 \%$ when the concentration was increased to $8 \mu \mathrm{g} / \mathrm{mL}$ at 24 and $72 \mathrm{~h}$ after magnetofection, respectively (Figure 4A-J). These results suggest that dose-dependent cytotoxicity of PEI-SPIONs when used as a transfection reagent was safe and nontoxic for transfection at concentrations $<8 \mu \mathrm{g} / \mathrm{mL}$. Therefore, PEISPIONs at $4 \mu \mathrm{g} / \mathrm{mL}$ were used in the remaining experiments of this study.

\section{Enhanced expression of PST and PSA-NCAM in PEI-SPIONs/PST/SCs}

The effects of PEI-SPIONs concentration and weight ratio of PEI-SPIONs/PST plasmids on the expression of PST
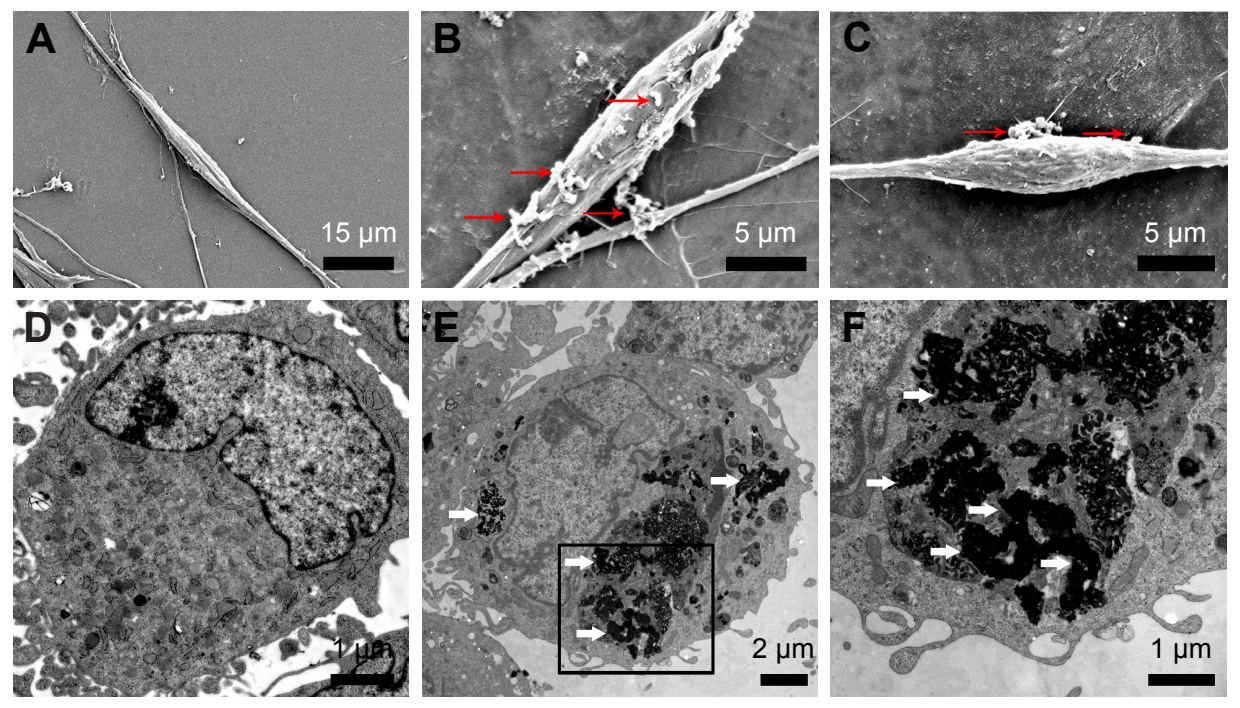

Figure 3 Cellular internalization of PEI-SPIONs.

Notes: (A) SEM photomicrograph of normal control SCs; no particles can be detected. (B and C) Six hours after magnetofection, SCs were treated with PEI-SPIONs $(4 \mu \mathrm{g} / \mathrm{mL})$; red arrows indicate the aggregated PEI-SPIONs on the cell surface. (D) TEM analysis of normal control SCs showed no PEI-SPIONs in the cytoplasm. (E and F) Twenty-four hours after magnetofection, SCs were treated with PEI-SPIONs (4 $\mathrm{gg} / \mathrm{mL})$; white arrows indicate the internalized PEI-SPIONs in the cytoplasm. (F) A higher magnification of the boxed area in (E).

Abbreviations: PEI-SPIONs, polyethylenimine-coated superparamagnetic iron oxide nanoparticles; SCs, Schwann cells; SEM, scanning electron microscopy; TEM, transmission electron microscopy. 

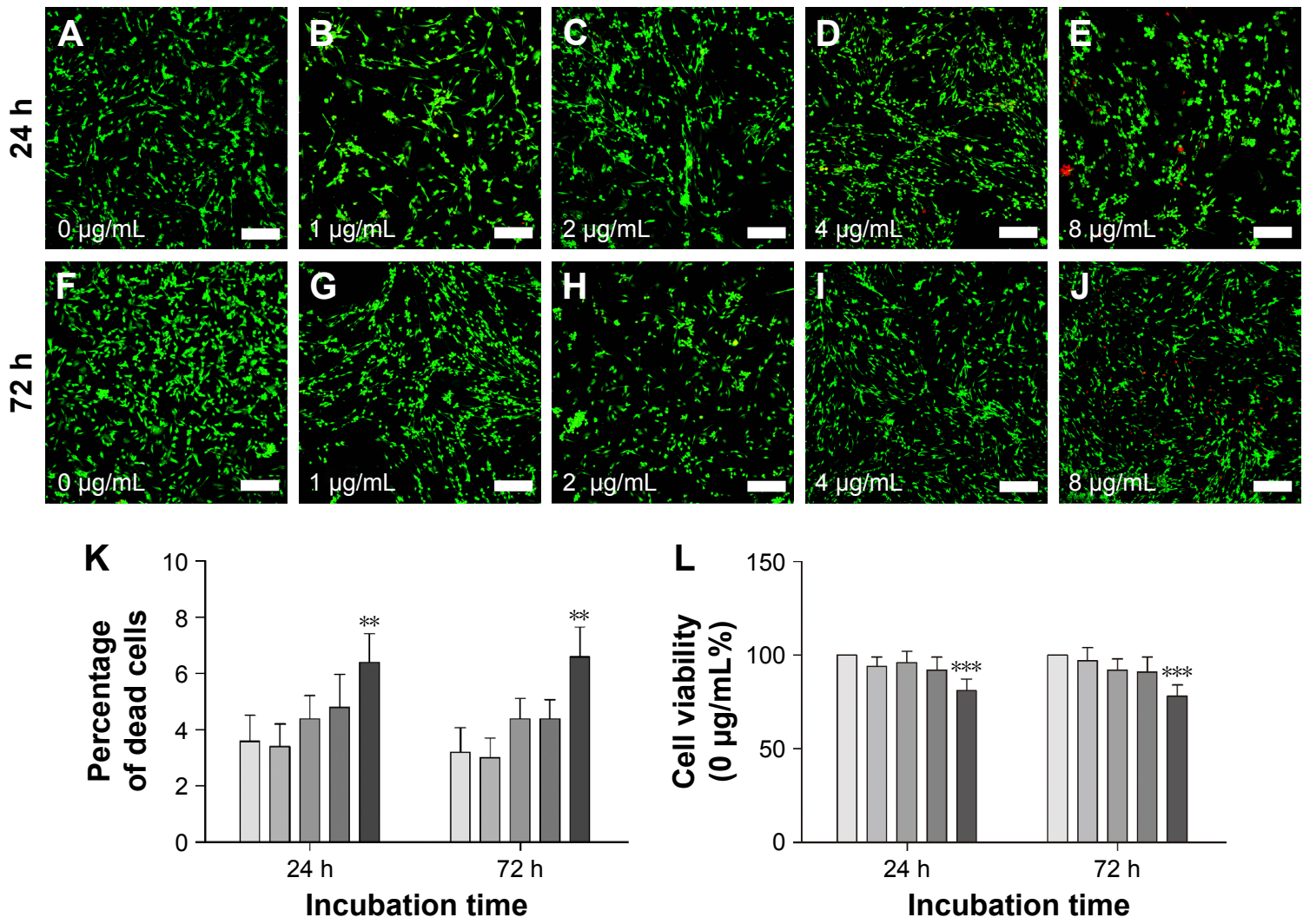

$0 \mu \mathrm{g} / \mathrm{mL} \square 1 \mu \mathrm{g} / \mathrm{mL} \square 2 \mu \mathrm{g} / \mathrm{mL} \square 4 \mu \mathrm{g} / \mathrm{mL} \square 8 \mu \mathrm{g} / \mathrm{mL}$

Figure 4 SC cytotoxicity tests of PEI-SPIONs.

Notes: SC cytotoxicity tests of PEI-SPIONs were carried out using live-dead staining and CCK-8 assay. Images of live-dead assay 24 h (A-E) and 72 h (F-J) after SCs were treated with different concentrations of PEI-SPIONs. (K) The percentage of dead cells was examined by live-dead assay. (L) Cell viability was evaluated by CCK-8 assay. Live cells were stained in green, while dead cells were stained in red. Scale bar: (A-J) $100 \mu \mathrm{m}$. Graph bars: mean \pm SD; $* * P<0.01$, $* * * P<0.005$.

Abbreviations: CCK-8, Cell Counting Kit 8; PEI-SPIONs, polyethylenimine-coated superparamagnetic iron oxide nanoparticles; SCs, Schwann cells; SD, standard deviation.

in PEI-SPIONs/PST/SCs were examined by real-time PCR. The mRNA level of PST was significantly enhanced when the concentration of PEI-SPIONs increased from 1 to $4 \mu \mathrm{g} / \mathrm{mL}$. Additionally, with the increase in weight ratio of PEI-SPIONs/PST plasmids from $1: 2$ to $1: 4$, the mRNA level of PST increased by 2.20 -fold at $1 \mu \mathrm{g} / \mathrm{mL}$ of PEI-SPIONs, 20.11-fold at $2 \mu \mathrm{g} / \mathrm{mL}$ of PEI-SPIONs, and 1.89 -fold at $4 \mu \mathrm{g} / \mathrm{mL}$ of PEI-SPIONs. It is noteworthy that the mRNA level of PST in SCs with $4 \mu \mathrm{g} / \mathrm{mL}$ PEI-SPIONs, and the weight ratio of 1:4 of PEI-SPIONs/PST plasmids, was 1,041-fold higher than that of normal control SCs (Figure 5A). The protein levels of PSA-NCAM in normal control SCs, control PEI-SPIONs/DNA/SCs $(4 \mu \mathrm{g} / \mathrm{mL}$, ratio of $1: 4)$, and PEI-SPIONs/PST/SCs $(4 \mu \mathrm{g} / \mathrm{mL}$, ratio of 1:4) were examined by Western blot analysis. PSA-NCAM protein was highly expressed in PEI-SPIONs/PST/SCs, while only a small amount was detected in the other groups (Figure 5B). The immunocytochemical results demonstrated that PSA-NCAM was highly expressed in PEI-SPIONs/PST/ $\mathrm{SCs}$ but not in normal control SCs (Figure 5C-H). These results suggest that PST was successfully transferred into SCs and that the exogenous PST enhanced the expression of PSA-NCAM in SCs.

\section{Directed and enhanced migration of PEI-SPIONs/PST/SCs on an astrocyte monolayer under an applied MF}

The inverted coverslip migration assay was carried out to investigate whether exogenous PST and PEI-SPIONs can be exploited to enhance the migration of SCs over an astrocyte monolayer and to manipulate the migration direction of SCs on application of an external MF (Figure 6). It was found that neither MF nor vector DNA magnetofection had a significant effect on the migration of SCs over an astrocyte monolayer (Figure 6A-C). In contrast, PST magnetofection increased the maximum migration distance of SCs over the astrocyte 


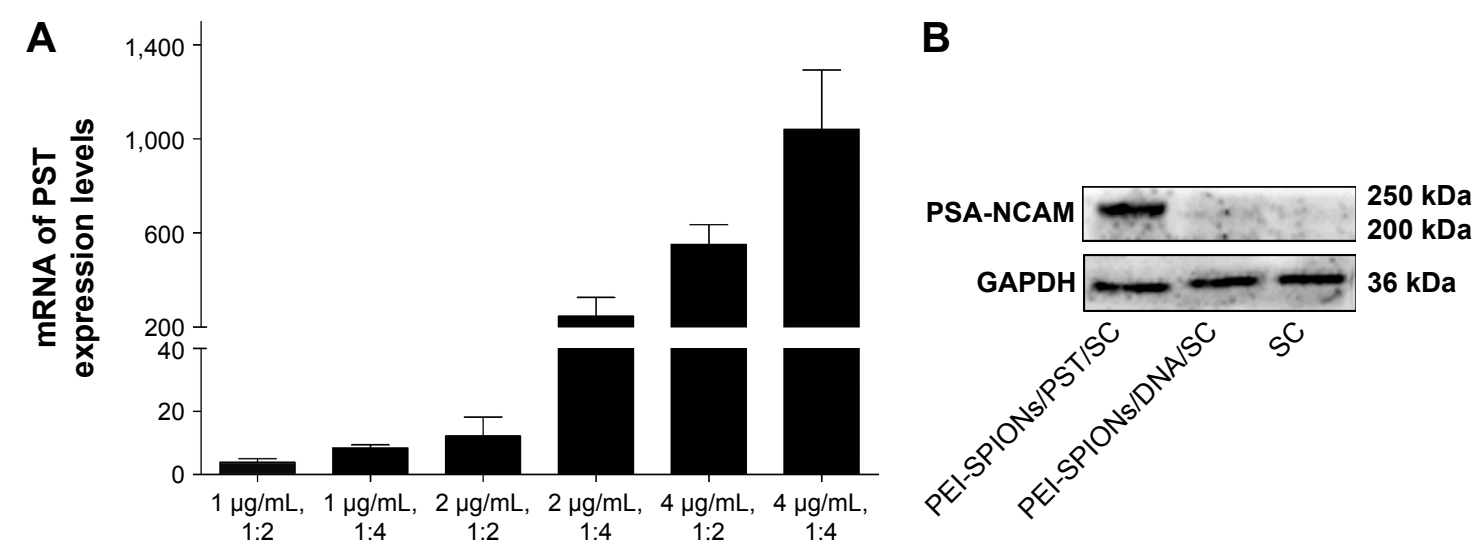

Different concentrations of PEI-SPIONs and different weight ratios of PEI-SPIONs/PST complexes
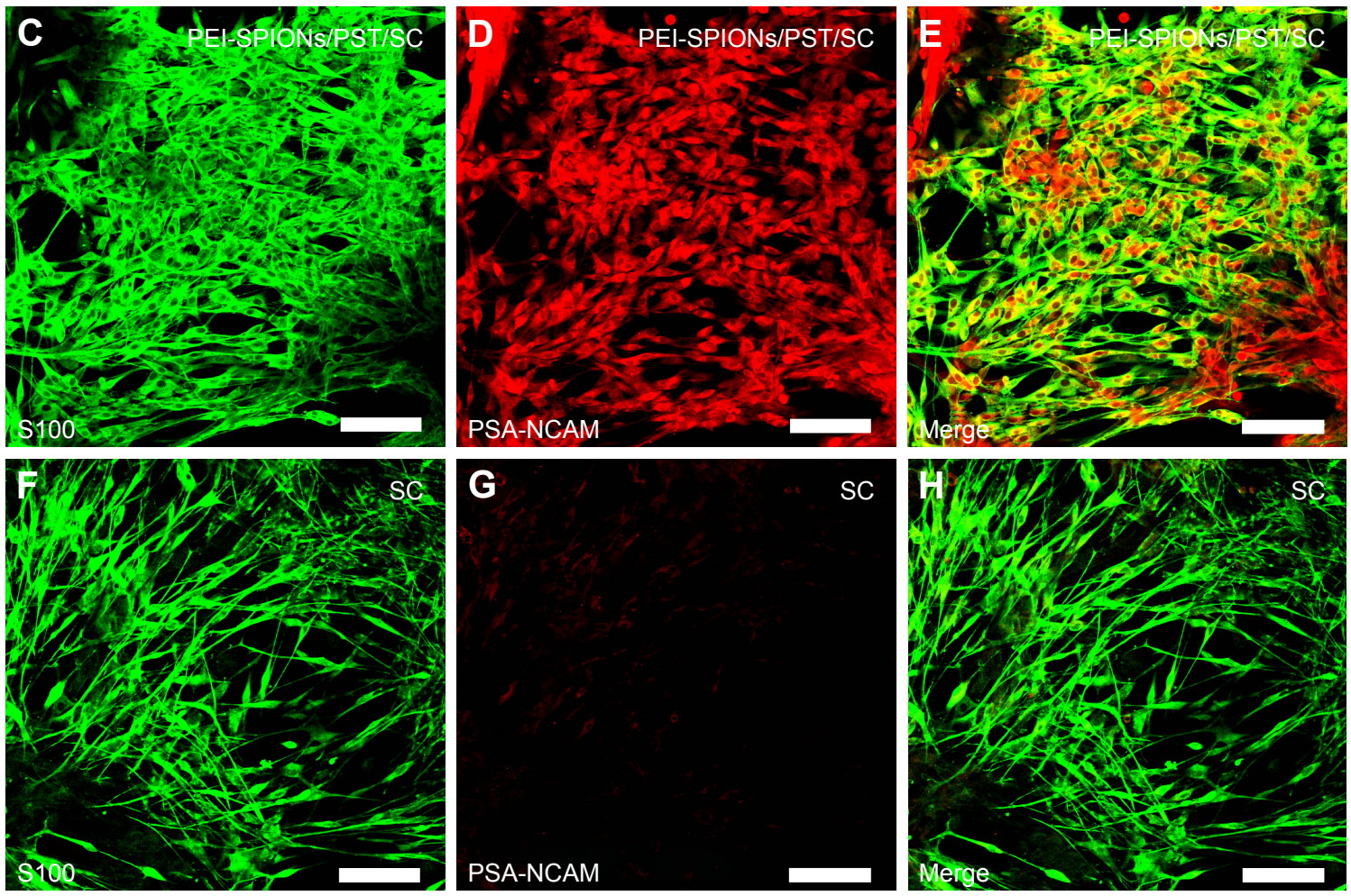

Figure 5 Expression and translation analyses of transferred exogenous PST.

Notes: (A) At $72 \mathrm{~h}$ after magnetofection, mRNA levels of PST in each group (already normalized by normal control SCs). (B) At $72 \mathrm{~h}$ after incubation/magnetofection, detection of PSA-NCAM expression in SCs, PEI-SPIONs/DNA/SCs, and PEI-SPIONs/PST/SCs by Western blotting. An obvious PSA-NCAM-specific band was detected in PEI-SPIONs/PST/SCs, while no PSA-NCAM-specific band was found in SCs and PEI-SPIONs/DNA/SCs. (C-E) At $72 \mathrm{~h}$ after magnetofection, confocal images showed the abundant expression of PSA-NCAM (red) in SI00-labeled PEI-SPIONs/PST/SCs (green). (F-H) No PSA-NCAM (red) was detected in SI00-labeled SCs (green). Scale bar: (C-H) $100 \mu \mathrm{m}$. Graph bars: mean \pm SD.

Abbreviations: mRNA, messenger RNA; PEI-SPIONs, polyethylenimine-coated superparamagnetic iron oxide nanoparticles; PSA-NCAM, polysialylated neural cell adhesion molecule; PST, polysialyltransferase; SCs, Schwann cells; SD, standard deviation.

monolayer (Figure 6E and I) but had no effect on migration orientation (Figure 6E, G, and H). When SCs magnetofected with PEI-SPIONs/vector DNA were subjected to an MF, both migration capacity and orientation were enhanced, as evidenced by a significantly increased orientation index, amounts of SCs in smaller angle groups, and maximum distance in the PEI-SPIONs/DNA/SC+MF group (Figure 6D, G-I). However, when SCs magnetofected with PEI-SPIONs/PST (PEI-SPIONs, $4 \mu \mathrm{g} / \mathrm{mL}$; PEI-SPION/PST, 1:4) were subjected to an MF, the migration capacity of SCs was further enhanced, and SCs migrated preferentially along the axis of the magnetic force on the astrocyte monolayer (Figure 6F-I). 
The orientation index in the PEI-SPIONs/PST/SC+MF group was significantly higher than that of the PEI-SPIONs/ $\mathrm{PST} / \mathrm{SC}$ and SC+MF groups (Figure 6G). Additionally, the highest maximum migration distance was achieved by the PEI-SPIONs/PST/SC+MF group (968.89 $\pm 161.76 \mu \mathrm{m})$, followed by the vector PEI-SPIONs/DNA/SC+MF group
$(480.89 \pm 105.37 \mu \mathrm{m})$, then the PEI-SPIONs/PST/SC group $(198.83 \pm 48.64 \mu \mathrm{m})$, and the least in the remaining groups (Figure 6I). The difference of maximal migration distance in the PEI-SPIONs/PST/SC+MF group is $>11$ times higher than the control SCs group $(83.33 \pm 18.26 \mu \mathrm{m})$. About 90\%-95\% cells migrated within $400 \mu \mathrm{m}$ away from the coverslips in the
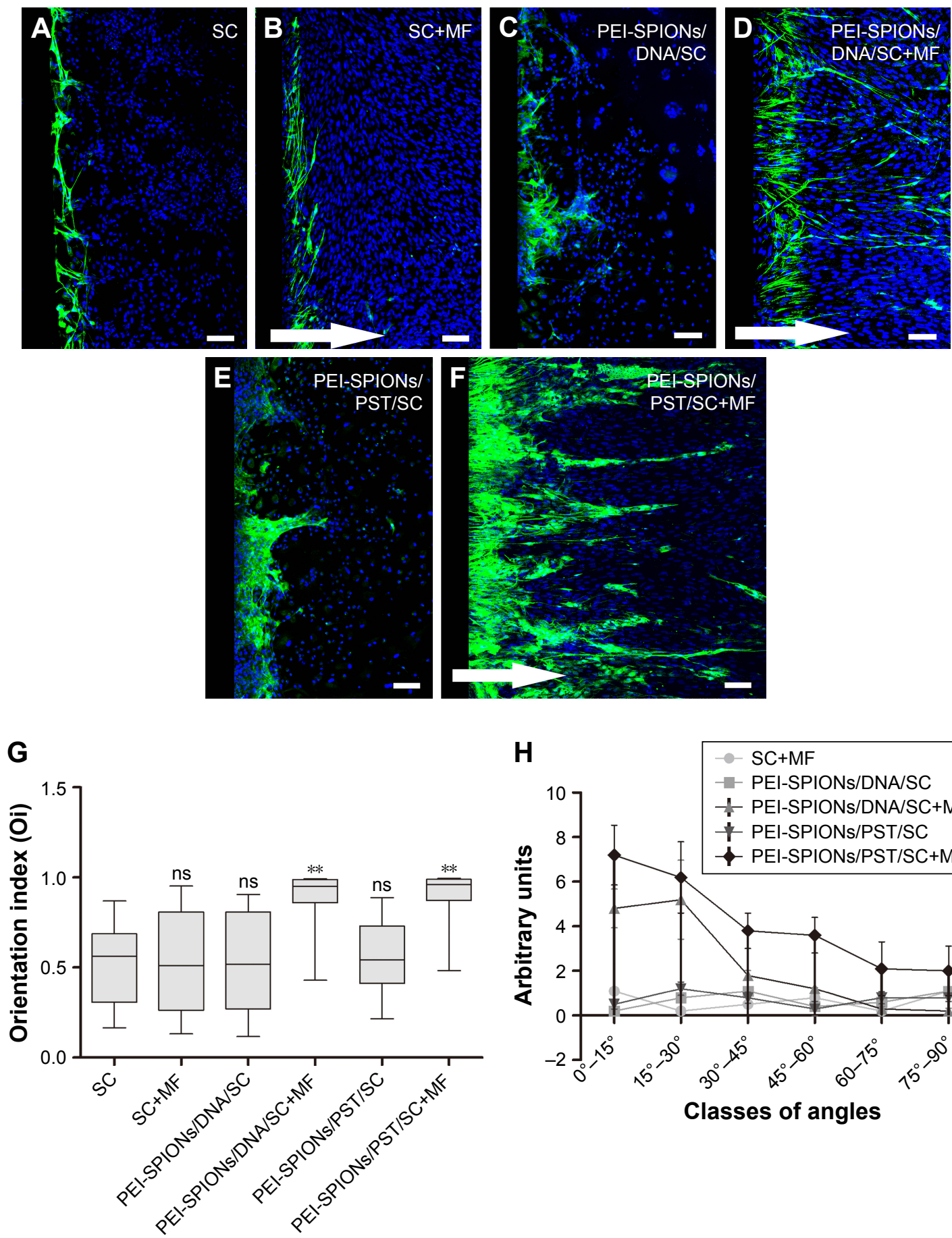

H

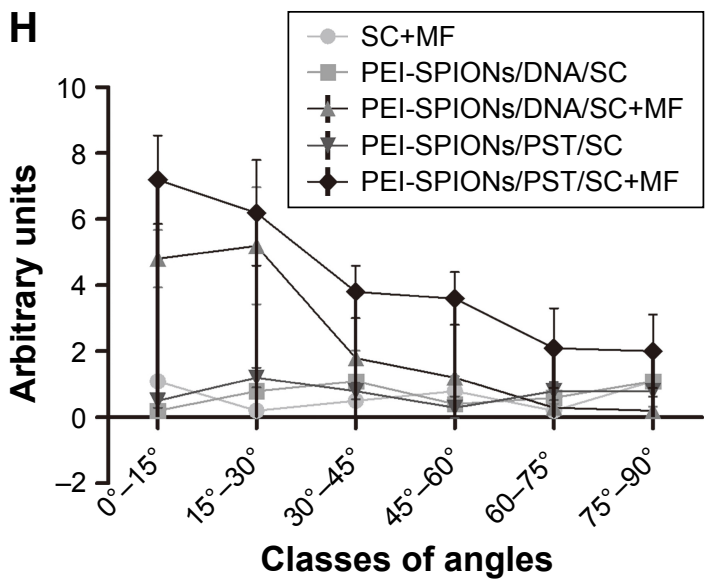

Figure 6 (Continued) 

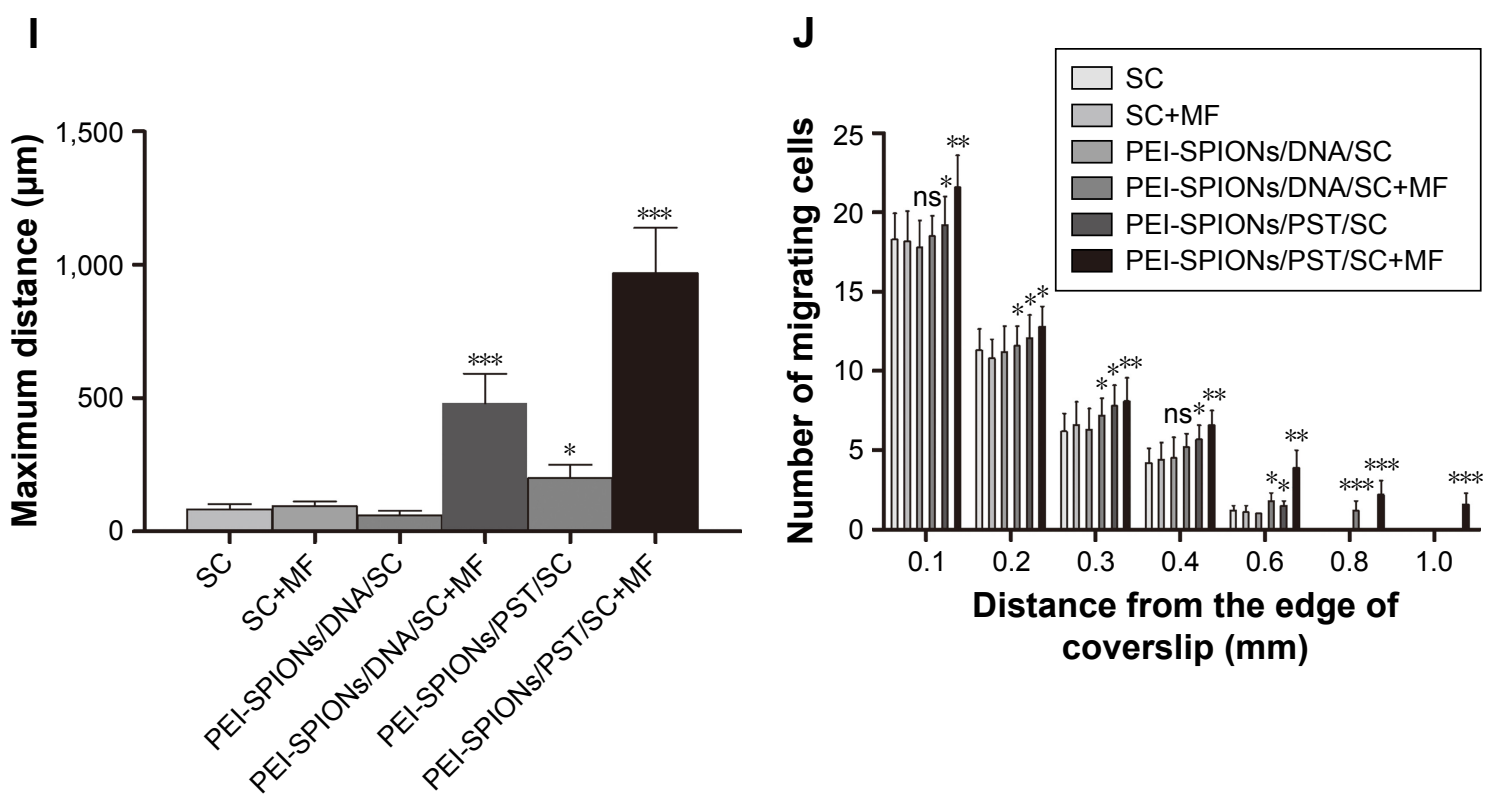

Figure 6 Representative images of SC migration in the inverted coverslip migration assay on an astrocyte monolayer.

Notes: (A-F) Astrocytes are only labeled with the nucleus staining solution DAPI (blue), while SCs are double-labeled with SI00 (green) and DAPI (blue). Arrows indicate the direction of the applied MF. (F) The migration of PEI-SPIONs/PST/SCs along the astrocyte monolayer is significantly enhanced and oriented parallel to the direction of magnetic force in the presence of an MF. (G) SC migration orientation index. The box-plot shows the median, interquartile ranges, maximum, and minimum. (H) Number of SCs (normalized by the normal control SCs for each group) grouped into classes of angles that were formed by the long axis of SCs and the direction of the external MF. (I) Average maximum distances migrated from the edge of the inverted fragments. (J) Number of SCs reaching different specific distances from the edge of an inverted fragment. Scale bar: $(\mathbf{A}-\mathbf{F}) 100 \mu \mathrm{m}$. Graph bars: mean \pm SD; Dunnett's test $* P<0.05, * * P<0.01, * * * P<0.005$.

Abbreviations: DAPI, 4',6-diamidino-2-phenylindole; MF, magnetic field; ns, not significant; PEI-SPIONs, polyethylenimine-coated superparamagnetic iron oxide nanoparticles; PST, polysialyltransferase; SCs, Schwann cells; SD, standard deviation.

control SCs group with or without MF and DNA/SC without MF. We choose $100 \mu \mathrm{m}$ distance section as a unit to count the number of migrated cells within $400 \mu \mathrm{m}$, and $200 \mu \mathrm{m}$ distance section for those that exceed $400 \mu \mathrm{m}$, for the number of cells at specific migration distance analysis (Figure 6J). It was also found that, in the presence of an MF, the number of PEISPIONs/PST/SCs $(56.8 \pm 9.72$ cells/500 $\mu \mathrm{m})$ that migrated away from the edge of the coverslips was significantly higher than that in the absence of an MF ( $46.3 \pm 6.47$ cells $/ 500 \mu \mathrm{m})$. Furthermore, the number of SCs that reached $0.2 \mathrm{~mm}$ from the edge of the coverslips in the PEI-SPIONs/DNA/SC+MF, PEI-SPIONs/PST/SCs, and PEI-SPIONs/PST/SC+MF groups was 1.02, 1.06, and 1.16 times higher than that of control SCs, respectively, which was $1.19,1.30$, and 1.41 times higher and $1.51,1.25$, and 3.25 times higher than that of control SCs that reached 0.4 and $0.6 \mathrm{~mm}$, respectively (Figure 6J). These findings indicate that PST magnetofection is able to promote migration capacity, and SPIONs with an applied MF are capable of directing the migration of SCs. When PEI-SPIONs/PST and an MF were applied simultaneously, the migration of SCs was enhanced and directed along the astrocyte monolayer.

\section{PEI-SPIONs/PST/SCs no longer form boundaries when in contact with astrocytes and their direction was oriented by' an applied MF}

We further performed confrontation assays to investigate whether PEI-SPIONs/PST/SCs could migrate into the astrocyte domain and break the boundaries with astrocytes (Figure 7). Cell boundaries were observed between astrocytes and normal SCs with or without an applied MF and PEISPIONs/DNA/SCs without an applied MF (Figure 7A-C), while PEI-SPIONs/PST/SCs and PEI-SPIONs/DNA/SCs broke the astrocyte boundaries and migrated preferentially along the axis of an applied MF (Figure 6D-F). No significant difference was found between the number of SCs that migrated into the astrocyte domain among SCs with or without an applied MF and PEI-SPIONs/DNA/SCs without an applied MF. Furthermore, the number of SCs that crossed the boundaries and migrated into astrocyte domain was highest in the PEI-SPIONs/PST/SC+MF group (44.67 \pm 6.18 ),

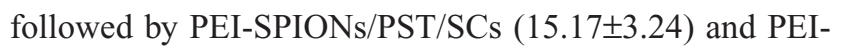
SPIONs/DNA/SC+MF (24.21士5.07), and least in SCs with 

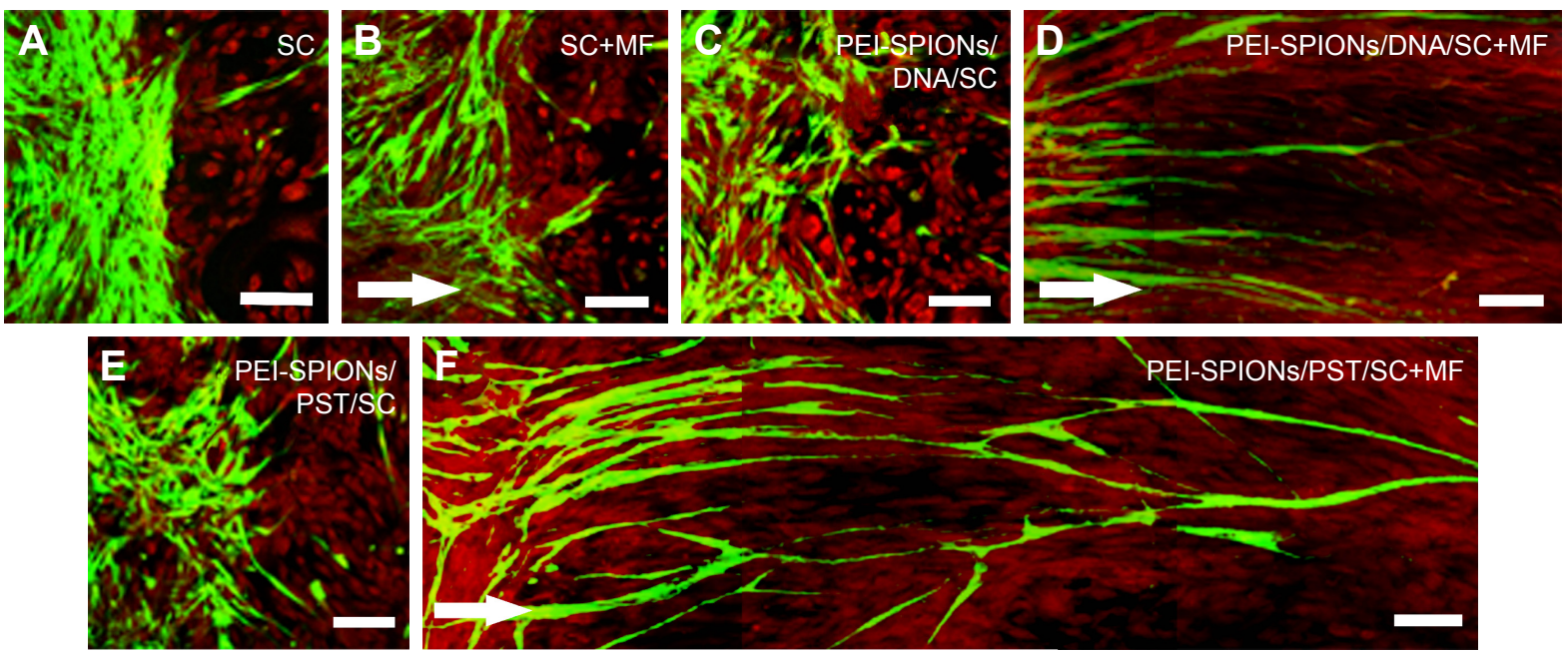

G

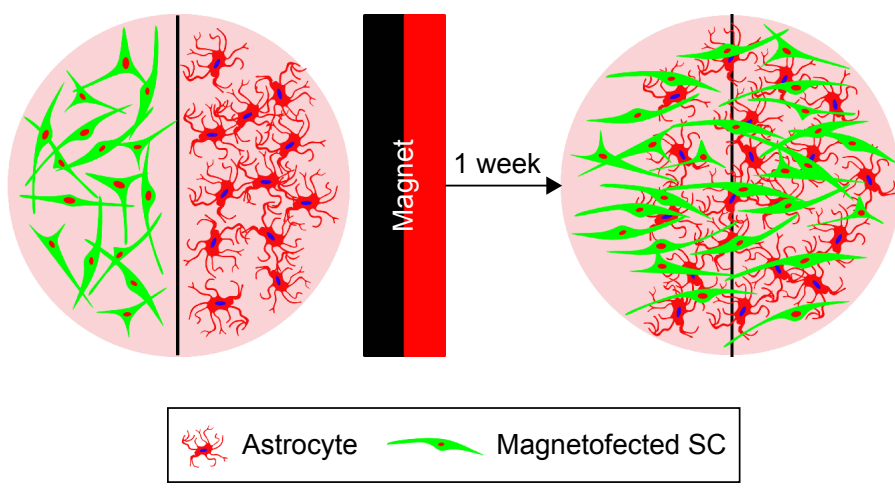

H

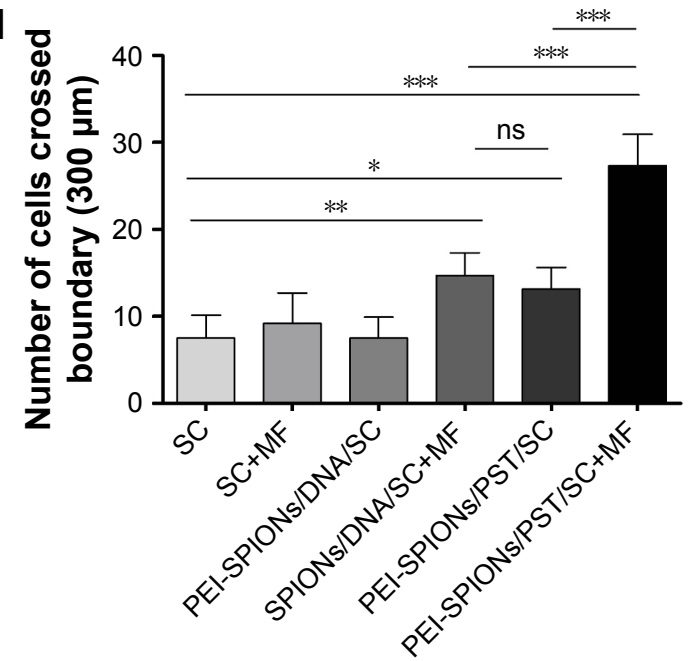

Figure 7 Confrontation assays of SCs and astrocytes.

Notes: Immonocytochemistry images of the SC-astrocyte confrontation assay. SCs are labeled with SI00 (green); astrocytes are labeled with GFAP (red). (A-F) Arrows indicate the direction of the MF. (A and B) SCs with and without an applied MF; boundaries both formed by astrocytes; (C) PEI-SPIONs/DNA/SCs formed a boundary with astrocytes in the absence of an applied MF; (D) PEI-SPIONs/DNA/SCs crossed the cell boundary in the presence of an MF. (E) PEI-SPIONs/PST/SCs migrated into the astrocyte domain while their migration had no specific direction; (F) PEI-SPIONs/PST/SCs thoroughly broke the boundary formed with astrocytes and aligned preferentially along the axis of the magnetic force under an applied MF. (G) Schematic diagram of the SC-astrocyte confrontation assay. Magnetofected SCs and astrocytes were plated in parallel strips, both were allowed to grow and migrate for $7 \mathrm{~d}$ under an applied MF. (H) Quantification of SCs that crossed the boundary and migrated into the astrocyte domain. The number of PEI-SPIONs/PST/SCs with an applied MF far exceeds those of the other groups. Scale bar: $(\mathbf{A}-\mathbf{F})$ I $00 \mu \mathrm{m}$. Graph bars: mean \pm SD; $* P<0.05$, $* * P<0.0$ I, $* * * P<0.005$.

Abbreviations: GFAP, glia fibrillary acidic protein; MF, magnetic field; ns, not significant; PEI-SPIONs, polyethylenimine-coated superparamagnetic iron oxide nanoparticles; PST, polysialyltransferase; SCs, Schwann cells; SD, standard deviation.

(6.67 \pm 1.71 cells) or without MF $(7.16 \pm 1.91$ cells $)$, as well as in PEI-SPIONs/DNA/SC without MF (7.27 \pm 2.41 cells) (Figure 7H). Additionally, the percentages of SCs that crossed the boundary and migrated into astrocyte territory at distances of 200,400 , and $>400 \mu \mathrm{m}$ in the PEI-SPIONs/ $\mathrm{PST} / \mathrm{SC}+\mathrm{MF}$ group were $51.3 \%, 26.1 \%$, and $22.6 \%$, while in the control SCs group, the percentages were $60.1 \%, 30.5 \%$, and $9.4 \%$, respectively.

\section{Discussion}

In this study, we found that PEI-SPIONs/DNA/SCs can be driven by an applied MF to break the cell boundaries of, and migrate into, the astrocyte domain. The number and maximum migration distance of PEI-SPIONs/DNA/SCs that migrated into the astrocyte domain were limited; this might be attributable to the poor migration ability of SCs in astrocyte domain. Therefore, SCs were magnetofected with PEI-SPIONs/PST, which is capable of upregulating the expression of PSA-NCAM on the cell membrane, and thus enhancing the migration ability of PEI-SPIONs/PST/ SCs. Encouragingly, PEI-SPIONs/PST/SCs migration was significantly increased with respect to both the number and maximum distance of cells migrating into the astrocyte domain with the assistance of an external MF, which 
resulted in efficient interminglement and integration of SCs into the astrocyte domain. This study developed a novel method to enhance and direct SC migration by internalized PEI-SPIONs/PST under an applied MF, which might be beneficial for the application of SCs in the repair of SCI.

SCs represent an attractive candidate for cell therapy of SCI. However, the efficacy of transplanted SCs in the treatment of $\mathrm{SCI}$ is limited by the poor migration and integration of SCs into astrocytes. ${ }^{6}$ Therefore, the use of genetically modified SCs with improved migration properties has gained much attention. Polysialylated NCAM is a mediator of neural cell migration and axon pathfinding. ${ }^{35}$ It has been reported that PST, a Golgiassociated PST, is capable of upregulating the synthesis of PSA on NCAM (polysialylated NCAM), thus enhancing the migration ability of SCs in injured CNS. ${ }^{36,37}$ However, the enhanced migration and integration of PST-modified SCs lack a specific direction in the CNS, posing a challenge for the integration of SCs into distal astrocytes after SCI.

SPIONs are the most commonly used magnetic nanoparticles for biomedical applications, due to their low toxicity, high chemical stability, and biocompatibility. ${ }^{38}$ SPIONs have been exploited for being amenable to manipulation by external magnetic forces for drug delivery, cell separation, and MRI. ${ }^{39,40}$ The surface of SPIONs was further modified through the attachment of a cationic polymer, such as PEI, rendering it positively charged and thus apt for cellular internalization. ${ }^{41-43}$ PEI-SPIONs could effectively absorb negatively charged PST plasmids via electrostatic attraction. ${ }^{44,45}$ After magnetofection, the PEI-SPIONs/PST complex was readily internalized into cells by magnetic force, as confirmed by TEM, which revealed the presence of SPIONs within cells. Additionally, PSA-NCAM was found to be highly expressed in PEI-SPIONs/PST/SCs in this study, further evidencing the internalization of PEI-SPIONs/PST into SCs. We also determined the toxicity of PEI-SPIONs to be dose-dependent. The cytotoxicity of PEI-SPIONs at concentrations $<8 \mu \mathrm{g} / \mathrm{mL}$ was negligible on primary SCs; therefore, PEI-SPIONs at the concentration of $4 \mu \mathrm{g} / \mathrm{mL}$ were used to avoid their potential SC cytotoxicity.

In this study, magnetofection was used to efficiently transfect plasmids into SCs. Magnetofection, the use of magnetic force to promote the uptake of PEI-SPIONs associated with aimed genes into target cells, has the advantages of simplicity, versatility, and high efficiency as a tool for gene transfection. ${ }^{46,47}$ Studies have shown that magnetofection is capable of ensuring the stable expression of target genes. It has been demonstrated that the associated expression efficiency is $\sim 72.3 \%$ at $120 \mathrm{~h}$ after magnetofection, while the gene expression efficiency of lipofectamine is just $40.32 \%$ at $48 \mathrm{~h}$ after transfection. ${ }^{23}$ Therefore, magnetofection was used to introduce PST plasmids into SCs, a manipulation that led to the upregulation of PST mRNA levels by 1,041-fold in PEI-SPIONs/PST/SCs (PEI-SPIONs, $4 \mu \mathrm{g} / \mathrm{mL}$; PEI-SPION/ PST, 1:4) over that of control SCs at $72 \mathrm{~h}$ after magnetofection. This upregulated PST expression was associated with the enhancement of SC migration ability, though without a preferential direction. Furthermore, we utilized the magnetic characteristics of the SPION magnetofection vectors to generate cellular tension through an external MF, which induced SC migration along a specific direction parallel to the magnetic force.

SCs have many advantages in the repair of injuries and demyelination diseases in the spinal cord. They support axon elongation by secreting growth-associated factors and providing guiding substrates. ${ }^{48}$ Grafted SCs are inhibited by astrocytes in the CNS, and a boundary is formed between them. This boundary is a barrier for regenerated axons to overcome, ${ }^{49}$ and many efforts have been made to genetically modify SCs to break these boundaries. It has been reported that PST-modified SCs can migrate into astrocytes,${ }^{34}$ while the number of SCs and their average maximum migration distance are yet to be enhanced. It has been shown previously that sufficient and preferentially aligned SCs are beneficial for inducing the formation of Büngner bands.$^{50} \mathrm{In}$ this study, we first magnetofected SCs by PST-functionalized SPIONs to induce overexpression of PSA-NCAM, thus enhancing the migration ability of the SCs, before manipulating the direction of SC migration with the assistance of an applied MF. We found that the number and averaged maximum distance of PEI-SPIONs/PST/SCs that migrated into the astrocyte domain were significantly enhanced by an applied MF. Notably, the PEI-SPIONs/PST/SCs migrated preferentially along the axis of the magnetic force, which may be beneficial for the formation of Büngner bands in the CNS. The complexity of the cytoarchitecture of the nervous tissue has not been well reflected in this study; reactions of other glial cells with magnetofected SCs remain still unclear. Even though astrogliotic scar formation at the graft-host interfaces has been suggested to be a major inhibitory barrier to axonal regeneration and is responsible, at least in part, for the failure of axonal regeneration after SCI, the effect of other glial cells on migration of SCs needs to be investigated in our further work. Additionally, we will perform in vivo experiments to examine the repair efficacy of PST-magnetofected SCs with MF on SCI animal models and optimize the next step for the associated parameters.

Although the mechanism by which MF-orientated SCs migrate into astrocytes with the aid of SPIONs is unclear, 
we may postulate that the magnetic forces acting on the SPIONs generate tensile forces on SCs, which may activate cell signaling channels or integrin signaling pathways to facilitate SC migration into the astrocyte domain. Future studies are needed to investigate the relationship between SPIONs concentration, forces exerted on a single cell, and the strength of the external static magnet. Additionally, the protocol for grafting magnetofected SCs to guide the growth and remyelination of regenerated axons must be optimized.

\section{Conclusion}

This study demonstrated that the SPIONs-mediated magnetofection of PST could effectively upregulate the expression of PSA-NCAM and could thereby enhance SC migration in an astrocyte-rich environment. Additionally, the migration of PEI-SPIONs/PST/SCs could be directed and oriented by an applied MF, which resulted in the efficient interminglement and integration of SCs and astrocytes. These findings raise the possibilities of enhancing the migration of transplanted SCs in the astrocyte-rich CNS in a specific direction and creating $\mathrm{SC}$ bridges in the CNS environment to guide regenerated axons to their distal destinations in the treatment of SCI.

\section{Acknowledgments}

This work was supported by the National Basic Research Program of China (973 Program No 2014CB542206), the National Key Research and Development Program (2016YFC1101700), the National Natural Science Foundation of China (81672148 and 81371947), and the Program for Changjiang Scholar and Innovative Research Team in University (IRT1053). We thank technicians Ms Lifeng Lan, Mr Haifeng Zhang, Mr Yongqiang Li, and Ms Chunmei Wang for their excellent technical assistance. We also thank Chemicell (Berlin, Germany) for their kindly provided information about magnetization of PEI-SPIONs.

\section{Disclosure}

The authors report no conflicts of interest in this work.

\section{References}

1. Ruff CA, Wilcox JT, Fehlings MG. Cell-based transplantation strategies to promote plasticity following spinal cord injury. Exp Neurol. 2012; 235(1):78-90.

2. Schroeder GD, Kepler CK, Vaccaro AR. The use of cell transplantation in spinal cord injuries. J Am Acad Orthop Surg. 2016;24(4): 266-275.

3. Fuhrmann T, Tam RY, Ballarin B, et al. Injectable hydrogel promotes early survival of induced pluripotent stem cell-derived oligodendrocytes and attenuates longterm teratoma formation in a spinal cord injury model. Biomaterials. 2016;83:23-36.

4. Huang L, Quan X, Liu Z, et al. c-Jun gene-modified Schwann cells: upregulating multiple neurotrophic factors and promoting neurite outgrowth. Tissue Eng Part A. 2015;21(7-8):1409-1421.
5. Afshari FT, Kwok JC, White L, Fawcett JW. Schwann cell migration is integrin-dependent and inhibited by astrocyte-produced aggrecan. Glia. 2010;58(7):857-869.

6. Blakemore WF, Franklin RJ. Transplantation options for therapeutic central nervous system remyelination. Cell Transplant. 2000;9(2): 289-294.

7. Iwashita Y, Fawcett JW, Crang AJ, Franklin RJ, Blakemore WF. Schwann cells transplanted into normal and $\mathrm{X}$-irradiated adult white matter do not migrate extensively and show poor long-term survival. Exp Neurol. 2000;164(2):292-302.

8. Kanno H, Pressman Y, Moody A, et al. Combination of engineered Schwann cell grafts to secrete neurotrophin and chondroitinase promotes axonal regeneration and locomotion after spinal cord injury. J Neurosci. 2014;34(5):1838-1855.

9. Muir EM, Fyfe I, Gardiner S, et al. Modification of N-glycosylation sites allows secretion of bacterial chondroitinase $\mathrm{ABC}$ from mammalian cells. J Biotechnol. 2010;145(2):103-110.

10. Afshari FT, Kwok JC, Fawcett JW. Astrocyte-produced ephrins inhibit Schwann cell migration via VAV2 signaling. J Neurosci. 2010;30(12): 4246-4255.

11. Liu J, Chau CH, Liu H, et al. Upregulation of chondroitin 6-sulphotransferase-1 facilitates Schwann cell migration during axonal growth. J Cell Sci. 2006;119(pt 5):933-942.

12. Papastefanaki F, Chen J, Lavdas AA, Thomaidou D, Schachner M, Matsas R. Grafts of Schwann cells engineered to express PSA-NCAM promote functional recovery after spinal cord injury. Brain. 2007;130(8): 2159-2174.

13. Ghosh M, Tuesta LM, Puentes R, et al. Extensive cell migration, axon regeneration, and improved function with polysialic acid-modified Schwann cells after spinal cord injury. Glia. 2012;60(6):979-992.

14. Suzuki M, Suzuki M, Nakayama J, et al. Polysialic acid facilitates tumor invasion by glioma cells. Glycobiology. 2005;15(9):887-894.

15. Angata K, Fukuda M. Polysialyltransferases: major players in polysialic acid synthesis on the neural cell adhesion molecule. Biochimie. 2003; 85(1-2):195-206.

16. Luo J, Bo X, Wu D, Yeh J, Richardson PM, Zhang Y. Promoting survival, migration, and integration of transplanted Schwann cells by over-expressing polysialic acid. Glia. 2011;59(3):424-434.

17. Sasaki T, Iwasaki N, Kohno K, et al. Magnetic nanoparticles for improving cell invasion in tissue engineering. J Biomed Mater Res A. 2008;86A(4):969-978.

18. Jiang S, Eltoukhy AA, Love KT, Langer R, Anderson DG. Lipidoidcoated iron oxide nanoparticles for efficient DNA and siRNA delivery. Nano Lett. 2013;13(3):1059-1064.

19. Steketee MB, Moysidis SN, Jin XL, et al. Nanoparticle-mediated signaling endosome localization regulates growth cone motility and neurite growth. Proc Natl Acad Sci U S A. 2011;108(47):19042-19047.

20. Krötz F, Tz F, Sohn HY, Gloe T, Plank C, Pohl U. Magnetofection potentiates gene delivery to cultured endothelial cells. J Vasc Res. 2003; 40(5):425-434.

21. Bradshaw M, Clemons TD, Ho D, et al. Manipulating directional cell motility using intracellular superparamagnetic nanoparticles. Nanoscale. 2015;7(11):4884-4889.

22. Krötz F, de Wit C, Sohn HY, et al. Magnetofection-A highly efficient tool for antisense oligonucleotide delivery in vitro and in vivo. Mol Ther. 2003;7(5):700-710.

23. Zhao X, Cui H, Chen W, et al. Morphology, structure and function characterization of PEI modified magnetic nanoparticles gene delivery system. PLoS One. 2014;9(6):e98919.

24. Du J, Tian C, Liu Y, Ling J, Wang Y. Azo-capped polysarcosineb-polylysine as polypeptide gene vector: a new strategy to improve stability and easy optimization via host - guest interaction. Colloids Surf B Biointerfaces. 2015;130:31-39.

25 . Bray D. Axonal growth in response to experimentally applied mechanical tension. Dev Biol. 1984;102(2):379-389.

26. Fass JN, Odde DJ. Tensile force-dependent neurite elicitation via antib1 integrin antibody-coated magnetic beads. Biophys J. 2003;85(1): 623-636. 
27. Kristian F, Jochen G. The biophysics of neuronal growth. Rep Progr Phys. 2010;73:9.

28. Liu Z, Huang L, Liu L, et al. Activation of Schwann cells in vitro by magnetic nanocomposites via applied magnetic field. Int J Nanomedicine. 2015;10:43-61.

29. Georgiou M, Golding JP, Loughlin AJ, Kingham PJ, Phillips JB. Engineered neural tissue with aligned, differentiated adipose-derived stem cells promotes peripheral nerve regeneration across a critical sized defect in rat sciatic nerve. Biomaterials. 2015;37:242-251.

30. Lakatos A, Franklin RJ, Barnett SC. Olfactory ensheathing cells and Schwann cells differ in their in vitro interactions with astrocytes. Glia. 2000;32(3):214-225

31. Lozano O, Mejia J, Masereel B, Toussaint O, Lison D, Lucas S. Development of a PIXE analysis method for the determination of the biopersistence of $\mathrm{SiC}$ and $\mathrm{TiC}$ nanoparticles in rat lungs. Nanotoxicology. 2012;6(3):263-271.

32. Lozano O, Mejia J, Tabarrant T, et al. Quantification of nanoparticles in aqueous food matrices using particle-induced X-ray emission. Anal Bioanal Chem. 2012;403(10):2835-2841.

33. Laloy J, Lozano O, Alpan L, et al. Can TiC nanoparticles produce toxicity in oral administration to rats? Toxicol Rep. 2014;1:172-187.

34. Muller D, Djebbara-Hannas Z, Jourdain P, et al. Brain-derived neurotrophic factor restores long-term potentiation in polysialic acid-neural cell adhesion molecule-deficient hippocampus. Proc Natl Acad Sci USA. 2000;97(8):4315-4320.

35. Theodosis DT, Rougon G, Poulain DA. Retention of embryonic features by an adult neuronal system capable of plasticity: polysialylated neural cell adhesion molecule in the hypothalamo-neurohypophysial system. Proc Natl Acad Sci U S A. 1991;88(13):5494-5498.

36. Zhang Y, Yeh J, Richardson PM, Bo X. Cell adhesion molecules of the immunoglobulin superfamily in axonal regeneration and neural repair. Restor Neurol Neurosci. 2008;26(2-3):81-96.

37. Tartaj P, Morales M, Veintemillasverdaguer S, Gonzalez-Carreno T, Serna CJ. The preparation of magnetic nanoparticles for applications in biomedicine. J Phys D Appl Phys. 2003;36:182-197.

38. Pilakka-Kanthikeel S, Atluri VS, Sagar V, Saxena SK, Nair M. Targeted brain derived neurotropic factors (BDNF) delivery across the bloodbrain barrier for neuro- protection using magnetic nano carriers: an in-vitro study. PLoS One. 2013;8(4):e62241.
39. Cicha I, Scheffler L, Ebenau A, Lyer S, Alexiou C, Goppelt-Struebe M. Mitoxantrone-loaded superparamagnetic iron oxide nanoparticles as drug carriers for cancer therapy: uptake and toxicity in primary human tubular epithelial cells. Nanotoxicology. 2016;10(5):557-566.

40. Lo YL, Chou HL, Liao ZX, et al. Chondroitin sulfate-polyethylenimine copolymer-coated superparamagnetic iron oxide nanoparticles as an efficient magneto-gene carrier for microRNA-encoding plasmid DNA delivery. Nanoscale. 2015;7(18):8554-8565.

41. Mykhaylyk O, Sobisch T, Almstätter I, et al. Silica iron oxide magnetic nanoparticles modified for gene delivery: a search for optimum and quantitative criteria. Pharm Res. 2012;29(5):1344-1365.

42. Iijima M, Yamazaki M, Nomura Y, Kamiya H. Effect of structure of cationic dispersants on stability of carbon black nanoparticles and further processability through layer-by-layer surface modification. Chem Eng Sci. 2013;85:30-37.

43. Plank C, Zelphati O, Mykhaylyk O. Magnetically enhanced nucleic acid delivery. Ten years of magnetofection-progress and prospects. Adv Drug Deliv Rev. 2011;63(14-15):1300-1331.

44. Singh R, Kostarelos K. Designer adenoviruses for nanomedicine and nanodiagnostics. Trends Biotechnol. 2009;27(4):220-229.

45. Dobson J. Gene therapy progress and prospects: magnetic nanoparticlebased gene delivery. Gene Ther. 2006;13(4):283-287.

46. Bae KH, Lee K, Kim C, Park TG. Surface functionalized hollow manganese oxide nanoparticles for cancer targeted siRNA delivery and magnetic resonance imaging. Biomaterials. 2011;32(1):176-184.

47. Bampton ET, Taylor JS. Effects of Schwann cell secreted factors on PC12 cell neuritogenesis and survival. $J$ Neurobiol. 2005;63(1):29-48.

48. Adcock KH, Brown DJ, Shearer MC, et al. Axon behaviour at Schwann cell - astrocyte boundaries: manipulation of axon signalling pathways and the neural adhesion molecule L1 can enable axons to cross. Eur J Neurosci. 2004;20(6):1425-1435.

49. Guan F, Wang X, He F. Promotion of cell migration by neural cell adhesion molecule (NCAM) is enhanced by PSA in a polysialyltransferasespecific manner. PLoS One. 2015;10(4):e124237.

50. Ribeiro-Resende VT, Koenig B, Nichterwitz S, Oberhoffner S, Schlosshauer B. Strategies for inducing the formation of bands of Bungner in peripheral nerve regeneration. Biomaterials. 2009;30(29): $5251-5259$.
International Journal of Nanomedicine

\section{Publish your work in this journal}

The International Journal of Nanomedicine is an international, peerreviewed journal focusing on the application of nanotechnology in diagnostics, therapeutics, and drug delivery systems throughout the biomedical field. This journal is indexed on PubMed Central, MedLine, CAS, SciSearch $®$, Current Contents $\AA /$ Clinical Medicine,

\section{Dovepress}

Journal Citation Reports/Science Edition, EMBase, Scopus and the Elsevier Bibliographic databases. The manuscript management system is completely online and includes a very quick and fair peer-review system, which is all easy to use. Visit http://www.dovepress.com/ testimonials.php to read real quotes from published authors. 